diafragma havia presença de múltiplos nódulos medindo aproximadamente $0,5 \mathrm{~cm}$ de diâmetro e coloração branco-acizentada. Em linfonodos mediastinais havia um aumento de volume com coloração branco-acizentado. Os demais órgãos apresentavam-se dentro dos padròes de normalidade. Após exame microscópico observou-se neoplasia primária de pulmào, caracterizada pela proliferação do epitélio brônquico, bronquiolar e alveolar, com arranjo papilar e tubulopapilar. Observaram-se ainda células cuboidais à colunares, contendo muitas vezes, secreção mucosa, alto pleomorfismo, nucléolos centrais com presença de figuras de mitoses atípicas e calcificação, indicando carcinoma broncogênico, com variante em carcinoma bronquioalveolar. No diafragma os nódulos eram compativeis com metástase do carcinoma broncogênico. Após análise concluiu-se que o animal veio à óbito devido a neoplasia pulmonar primária de caráter maligno, diagnosticado como carcinoma broncogênico, culminando em uma insuficiência pulmonar.

\title{
82 - Estudo histoquímico da matriz extracelular de tumores de partes moles
}

Pinheiro, M. L.'; Xavier, J. G.

1- Universidade Paulista (UNIP), São Paulo-SP

A matriz extracelular (MEC) é um elemento fundamental dos tecidos, vinculado à sua forma e função. Seus componentes são produzidos pelas células locais, principalmente os derivados mesodérmicos. Nas neoplasias provenientes dessas células, os chamados tumores de partes moles, freqüentemente identifica-se importante deposição de MEC. Este trabalho objetiva investigar a possibilidade da utilização das características da MEC no diagnóstico diferencial de tumores de partes moles de cães com o emprego de métodos histoquímicos. Foram selecionados 28 casos de neoplasias de partes moles atendidas no HOVET/UNIP e diagnosticadas no Laboratório de Patologia da mesma instituição. Cada caso foi estudado com a utilização dos métodos histoquímicos: hematoxilina/eosina, PAS, azul de Alcian, tricrômico de Masson, Gordon \& Sweets, Picrossírius, hematoxilina férrica de Verhoeff, avaliando-se a constituição, a quantidade (expressa em escores) e o padrão de distribuiçào dos componentes da MEC. Identificou-se grande semelhança entre os padròes de organização da $\mathrm{MEC}$ em neoplasias de fibroblastos e de células musculares lisas, com o predomínio de fibras colágenas delgadas dispostas em fascículos. Nos schwannomas observou-se freqüentemente arranjo concêntrico das fibras, podendo associar-se sua agregaçào em "espinha-de-peixe". Arquitetura concêntrica semelhante de fibras colágenas foi identificada em hemangiopericitomas, porém em sítios perivasculares. Outra característica que os difere é que os hemangiopericitomas apresentam menor quantidade de fibras e de mucopolissacarídeos ácidos. A distribuição das fibras colágenas em padrào alveolar predomina em lipossarcomas, rabdomiossarcomas e hemangiossarcomas. Porém, neste último caso, a delimitação de pequenas lojas relaciona-se à parede dos vasos neoplásicos. De maneira geral, as formas malignas deste grupo de tumores apresenta mais fibras que as formas benignas. É observada a presença de glicoproteínas neutras em todos os tumores, exceto nos fibrossarcomas, schwannomas e hemangiopericitomas; já os mucopolissacarídeos ácidos sào observados em todos os tumores em pequena quantidade. Nos lipossarcomas, ao se utilizar o método de Picrossírius, não foi possivel identificar nenhum tipo de fibra colágena, identificando-se discreta reatividade com o tricrômico de Masson. O método de Verhoeff não se mostrou adequado para a avaliação desses processos pela inexistência de fibras elásticas em todos os casos. Através do presente trabalho, foi possivel verificar que o uso da histoquímica pode funcionar como método auxiliar no diagnóstico diferencial de tumores de partes moles, associando-se aos achados morfológicos em cortes corados pela hematoxilina/eosina. Mostraram-se particularmente relevantes os métodos de 
Picrossírius e Gordon \& Sweets, permitindo a caracterização das populações colagênicas, sua quantidade e distribuição. Tal fato reveste-se de importância dada a grande sobreposiçào de características morfológicas presentes nesses processos e pela limitação do uso de outras técnicas, como a imunoistoquímica, devido ao seu elevado custo e a ausência de marcadores específicos em certos tumores.

\section{3 - Linfoma felino de grandes grânulos. Relato de caso}

Marcondes Santos, M.'; Franchini, M. $\mathrm{L}^{5}$; Merlo, $\mathrm{A}^{1}$; Silva,P.T.D; Fragata, F. S; Kozu, F.O. ${ }^{3}$ Felizzola, C. R. ${ }^{6}$
1- Departamento de Clínica Médica do Hospital Veterinário Sena Madureira, São Paulo-SP

2- Departamento de Anestesiologia do Hospital Veterinário Sena Madureira, São Paulo-SP

3- Departamento de Videolaparoscopia do Hospital Veterinário Sena Madureira, São Paulo-SP

4- Departamento de Anátomo-patológico do Hospital Veterinário Sena Madureira, São Paulo-SP

5- Médico Veterinário autônomo

6- Pós-doutoranda da Faculdade de Odontologia da Universidade de São Paulo, São Paulo-SP

Uma porcentagem variável de linfócitos normais no homem e em animais podem ter grandes grânulos azurófilos citoplasmáticos. Esses linfócitos são denominados de linfócitos de grandes grânulos e no homem a maioria destes sào caracterizados como células naturalKiller (NK). Em felinos hígidos raramente estas células são observadas na circulação sanguínea e medula óssea. Algumas desordens linfoproliferativas envolvendo estes linfócitos foram observadas no homem e felinos, foi descrita como linfoma de grandes grânulos. As manifestações clínicas mais freqüentes na espécie são distúrbios gastrintestinais como anorexia, emese, diarréia e perda de peso. Histologicamente pode-se observar infiltrado de células tumorais em parede intestinal, figado, baço, pâncreas, rins e miocárdio. Não foi encontrado descrição deste tipo de linfoma em felinos no Brasil. O objetivo do relato é descrever a evolução clinica de um felino com linfoma de grandes grânulos bem como as alterações encontradas nos exames complementares realizados. Um felino sem raça definida, 12 anos, foi atendido no Hospital Veterinário Sena Madureira com quadro de emagrecimento e hiporexia há 15 dias, desidratação leve e mucosas ictéricas. Foram realizados ultra-som de abdômen (hepatomegalia com ecogenicidade reduzida, esplenomegalia), urinálise (bilirrubinúria), bioquimicos (ALT=217,4 UI/L; AST= 383,9 UI/L; FA= 192,4 UI/L; Bilirrubina total $=6,1$; direta $=4 \mathrm{e}$ indireta $=2,1 \mathrm{mg} / \mathrm{dl}$; proteina total $=7,6 \mathrm{~g} / \mathrm{dl}$; albumina $=$ $2,1 \mathrm{~g} / \mathrm{dl}$ e globulina $=5,5 \mathrm{~g} / \mathrm{dl} ; \mathrm{GGT}=3,2 \mathrm{UI} / \mathrm{L} ;$ uréia $=24,5 \mathrm{mg} / \mathrm{dl}$ e creatinina $=1,1 \mathrm{mg} /$ dl e hemograma (leucopenia e presença de linfócitos com grandes grânulos azurofilicos). Foi realizada colocaçào de gastrotubo e biópsia hepática por videolaparoscopiam, onde foi coletado material para histopatologia que revelou infiltrado de linfócitos pequenos com citoplasma escasso com ausência de atipia. Realizou-se citologia aspirativa de baço e figado guiada por ultra-som, sendo as lâminas coradas pelo método Rosenfeld, observando-se predomínio de células linfóides com grandes grânulos azurófilos intracitoplasmáticos em ambos os órgãos. Pela análise dos resultados diagnosticou-se o linfoma felino de grandes grânulos. Realizaram sorologias para imunodeficiência e leucemia felinas, ambas negativas. Instituiu-se inicialmente o tratamento com ampicilina e dieta pelo gastrotubo e, com o resultado do histopatológico, citologia e hemograma, ambos sugerindo linfoma, iniciou-se a quimioterapia (metotrexato e ciclofosfamida), evoluindo inicialmente com melhora do estado geral e diminuiçào da icterícia, porém, mantendo-se anorético. $\mathrm{O}$ ultra-som controle indicou linfoadenomegalia de linfonodos mesentéricos. Após quinze dias do início da quimioterapia o animal apresentou quadro de dispnéia e prostração vindo a óbito, não sendo autorizada a necrópsia pelo proprietário. 